\title{
THE VENOUS DRAINAGE OF THE ACCESSORY REPRODUCTIVE ORGANS OF THE RAT WITH SPECIAL REFERENCE TO PROSTATIC METABOLISM
}

\author{
M. H. LEWIS AND D. B. MOFFAT \\ Anatomy Department, University College, Cardiff
}

(Received 22nd Fuly 1974)

\begin{abstract}
Summary. The venous drainage of the testis, epididymis, prostate and bladder was studied in live and recently dead rats. New evidence for a previously suggested direct venous connection between the epididymis and the prostate is presented, and a mechanism for blood flow from the deferential vein into the prostatic venous plexus under conditions of raised central venous pressure is described. The studies have also revealed discrepancies among previous reports which might be resolved by a simplified nomenclature.
\end{abstract}

\section{INTRODUCTION}

Although the arterial supply of the pelvic viscera of the rat has been well documented (Harrison, 1949a; MacMillan, 1953; Greene, 1968; Kormano, $1967,1968)$, studies of the venous system have concentrated either on comparative aspects of the visceral veins or on the drainage of single organs (Harrison, 1949a, b; MacMillan, 1953; Kormano, 1968; Setchell, 1970). The general account produced by Greene (1968) is insufficiently detailed to permit investigation of possible venous connections between individual organs of the genital tract. Pierrepoint and his colleagues raised the possibility of such a connection between the cauda epididymidis and the prostate and postulated that this might be the mechanism for a direct and unilateral control of the prostate and seminal vesicle mediated through the deferential vein (Pierrepoint \& Davies, 1973; Pierrepoint, 1974; Pierrepoint, Davies \& Wilson, 1974; Pierrepoint, Davies, Millington \& John, 1975). Skinner \& Rowson (1968) have also demonstrated unilateral hypertrophy of the ampulla following injection of testosterone into the ductus deferens of castrated pubescent rams and bulls. The studies reported here were undertaken to examine this possibility, and to provide detailed information on the venous drainage of the rat testis, epididymis, prostate and bladder.

\section{MATERIALS AND METHODS}

Thirty-six adult rats of various strains, including Sprague-Dawley, Wistar and wild animals, weighing between 150 and $300 \mathrm{~g}$, were used. Thirty were killed by ether inhalation before injection of either Neoprene latex (Harris Ltd, 
Ludgate, Birmingham) diluted $50 \%$ with water (twenty-seven rats) or Indian ink (Pelikan-Gunther, Wagner) (three rats) caudally into the posterior vena cava through a cannula tied securely into the vessel to prevent leakage. The thoracic aorta was severed to allow the escape of arterial blood during the infusion. No attempt was made to inject at a physiological pressure although the injection never produced marked distension or rupture of the abdominal vessels. The urinary bladder was then filled with $50 \%$ Neoprene latex through the urethra. The specimens were fixed by immersion in acidified formalin solution and then dissected, using a binocular dissecting microscope. In three other animals the arterial and venous systems were injected with differently coloured latex solutions in order to illustrate arterio-venous relationships. Specimens of various portions of the vascular system were removed and fixed in formalin for histological examination.

Six rats were anaesthetized by intraperitoneal administration of pentobarbitone sodium (Nembutal: Abbott Laboratories), $25 \mathrm{mg} / \mathrm{ml}$ and $0.35 \mathrm{ml} / 100 \mathrm{~g}$ body wt, and the abdomen was opened by a mid-line incision. A drawn-out glass microcannula was inserted into the deferential vein close to its origin in the cauda epididymidis and $0.5 \mathrm{ml}$ of a filtered, saturated solution of Thioflavine S (George T. Gurr Ltd, London), as previously described by Fourman \& Moffat (1971), was slowly injected in the direction of the blood flow. The rate at which this fluorescent dye was allowed to enter the blood stream was such that no interference in flow could be observed through the dissecting microscope. Since we had found that the fluorescent material reappeared at the site of injection in $10 \mathrm{sec}$, a maximum of $5 \mathrm{sec}$ was allowed from the commencement of the infusion before clamping the prostate at its base to prevent contaminated arterial blood from affecting the results. The outer surface of the prostate was then washed in isotonic saline, again to ensure that contamination had not occurred, and rapidly cooled to the temperature of a mixture of acetone and dry-ice. Frozen sections were cut at $20 \mu \mathrm{m}$ on a Cambridge cryostat and these were dehydrated, mounted in DePeX (George T. Gurr Ltd, London) and examined with a Reichert fluorescence microscope. During the Thioflavine injections, the rats were placed in one of two positions-either head up with the body at $60^{\circ}$ to the horizontal or supine. In all cases, the testis of the injected side was similarly examined as a further confirmation that recirculation of the dye had not occurred.

\section{RESULTS}

The following account of the venous system of the pelvic viscera of the male rat is based on our studies. We use a revised terminology, and when differences from that of Greene (1968) occur, the old names are in parentheses. Veins from the testis, epididymis (excluding the cauda) and epididymal fat converge in the region of the anterior pole of the testis to form the pampiniform plexus which surrounds the testicular (internal spermatic) artery. This plexus enters the abdomen by way of the inguinal canal and drains predominantly to the hypogastric (superior vesical) vein on each side (Text-fig. 1). Only two small venae comitantes accompany the testicular (internal spermatic) arteries along their 
whole length and these enter the left renal vein and the posterior vena cava on the left and right sides respectively. The cauda epididymidis is drained mainly by the deferential vein although a small anastomosis between the epididymal branch of the testicular vessels and the deferential vessel is a constant finding. The deferential vein commences by the confluence of a number of tributaries in the scrotum, runs in a small mesentery to the cauda epididymidis and then accompanies the ductus as one or two veins, the deferential vein(s), to the

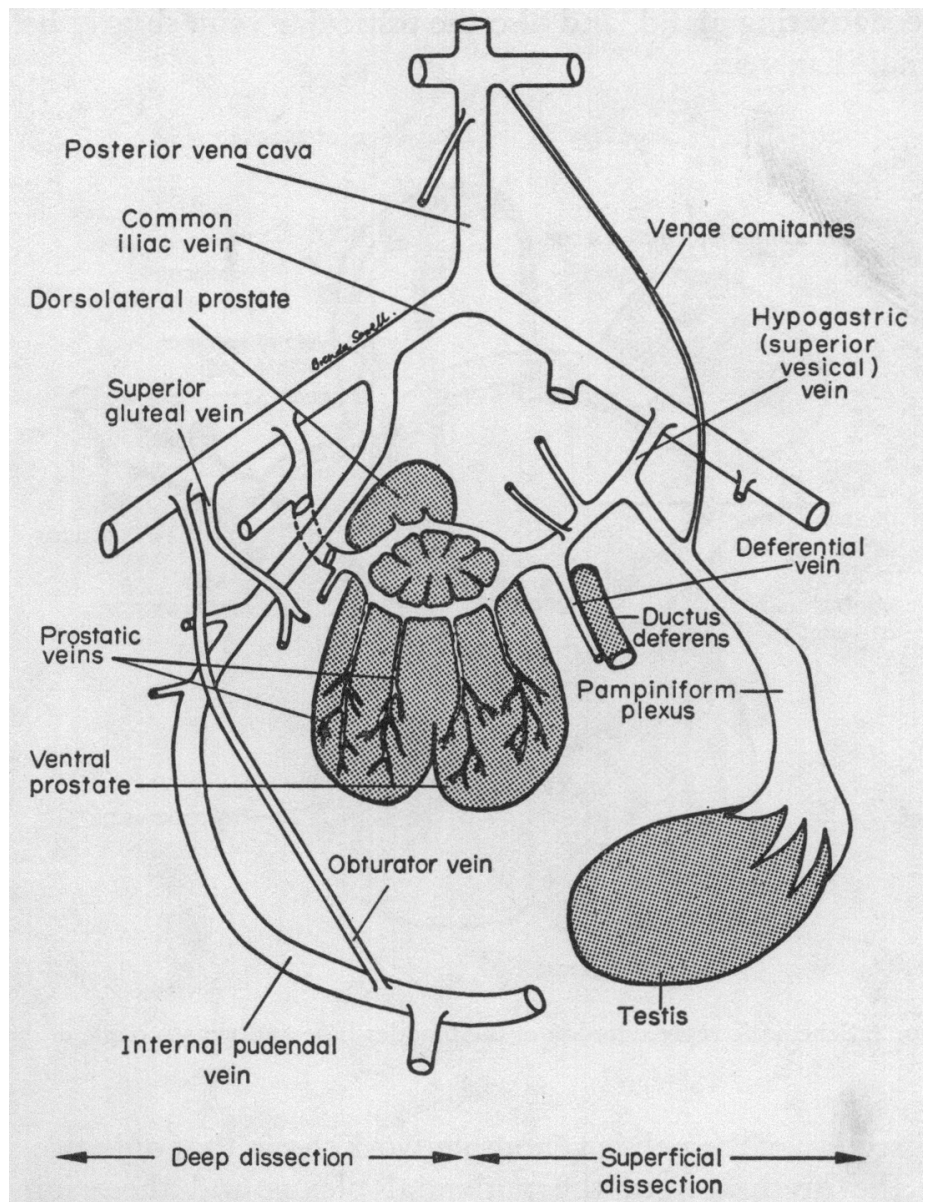

TeXT-FIG. 1. Schematic representation of the pelvic venous system in the male rat.

hypogastric (superior vesical) vein (Text-fig. 1). The bladder and prostate are drained by an hitherto undescribed, single, large, circular venous anastomosis which surrounds the base of the bladder (Text-fig. 2). The circle is formed by ventral and dorsal veins which unite laterally to form the hypogastric (superior vesical) vein of both sides (Text-fig. 1). The ventral and dorsolateral prostatic lobes are drained directly by straight veins into the adjacent parts of the venous circle. These veins in the ventral prostatic lobes have previously been called inferior vesical veins but the term 'prostatic veins' seems more suitable. The 
tortuous veins on the bladder wall pass directly into the circle. These findings are shown schematically in Text-fig. 1. Only two small tributaries of the venous circle (omitted from the Text-figures) are present on the under side of the ventral prostate: they have no communication with the gland and will be described later.

The deferential vein(s) enters the hypogastric vein immediately lateral to its origin from the union of the ventral and dorsal parts of the venous circle. More laterally, the hypogastric vein receives a large tributary from the seminal vesicle and coagulating gland, and also the testicular vein, shortly before it ends in the external iliac vein.

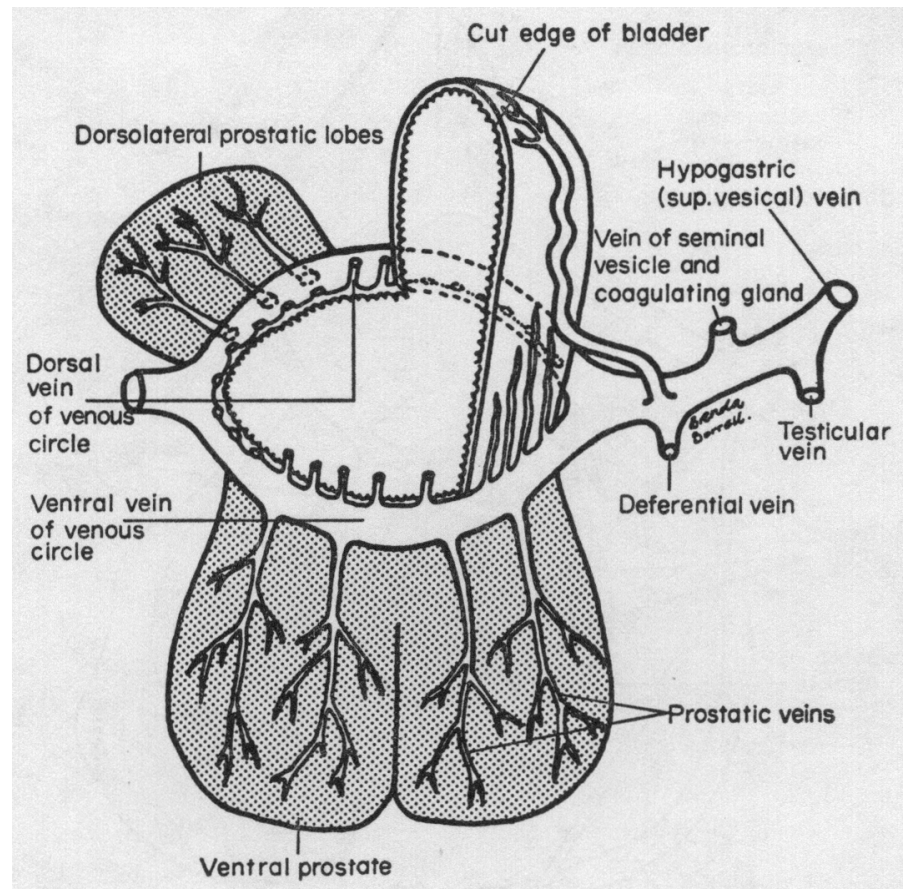

Texr-Fic. 2. Schematic representation of the bladder base and venous circle of the male rat.

A deep dissection of the pelvic venous network shows that only two small veins accompany the urethra from the pudendal plexus and these join the deep ventral surface of the venous circle at the base of the bladder. They pass ventral to the ventral lobes of the prostate but have no further connection with them. Both the internal pudendal and obturator vessels end in the common iliac veins, and have no other communication with the prostatic venous system.

Our examinations of the arterial supply of the pelvic viscera agreed with the reports of previous authors, and no further details are given here. At sites of arterio-venous proximity (e.g. hypogastric artery and vein; deferential artery and veins), histological sections showed no sign of arterio-venous anastomoses or any modifications to vessel structure suggesting exchanges of intravascular materials. 
Of the six rats injected with Thioflavine $S$, two showed fluorescence in the veins at the periphery of the prostate although no Thioflavine was found in the intrinsic vessels of the gland. Both of these positive results were obtained with the rats in the $60^{\circ}$ head up position; of the four negative results, two animals were head up and two in the supine position.

\section{DISGUSSION}

In previous reports, Pierrepoint and his associates postulated the existence of an androgen carrier mechanism from the testis and epididymis to the prostate (Pierrepoint \& Davies, 1973), and suggested that the route of androgen transport from the site of production in the tail of the epididymis to the prostate might be along the deferential vein (Pierrepoint, Davies, Millington \& John, 1975). The results of the present studies strongly support the anatomical possibility of such a transport mechanism. The deferential vein terminates in close proximity to the prostatic plexus, and a free venous communication has been demonstrated between them for the first time. The experiments using Thioflavine showed that deferential vein blood can enter the prostatic plexus, and this was confirmed at dissection in three animals when Indian ink, injected at low pressure into the deferential vein, flowed freely into the venous circle and prostatic veins. Since histological examination of hypogastric, prostatic and venous circle veins failed to demonstrate any valves, free flow of blood from the cauda epididymidis to the prostate is possible.

In intact animals, such flow is probably intermittent, occurring only when forward flow in the hypogastric vein is slowed or reversed by physiologically raised intrathoracic or intra-abdominal pressure. Similar valveless veins have been described in man, connecting the prostatic venous plexus with the extradural vertebral veins (Batson, 1940). Reversed flow along these veins has been incriminated in the early spread of prostatic carcinoma to the spine (Batson, 1940; Franks, 1953). It is probably of significance that the two positive results using Thioflavine injection occurred when the rats were in the $60^{\circ}$ head up position, hence encouraging reversed flow in the pelvic veins.

The veins of the pelvic viscera of the rat are remarkably constant in their position and connections. Nevertheless, the nomenclature for some of the veins proposed by Greene (1968) seems unsatisfactory. The vein which commences at the lateral aspect of the venous circle and passes to the external iliac vein was called the 'superior vesical' vein. But since it drains not only the bladder, but also the prostatic plexus, cauda epididymidis, seminal vesicle and coagulating gland, it would be better called the 'hypogastric' vein. The so-called 'inferior vesical' veins pass from the ventral prostatic lobes to the most proximal part of the venous circle, and since they take no part in draining the bladder they would be better described as 'prostatic' veins. The term 'vesical' veins should be reserved for the small coiled veins of the bladder wall, which pass to the adjacent venous circle.

Finally, Greene (1968) observed an asymmetrical drainage of the right and left pampiniform plexuses - the right apparently joined the posterior vena cava directly whilst the left entered the left hypogastric (superior vesical) vein. In the 
present study, however, the right and left pampiniform plexuses were found to drain into the right and left hypogastric vessels respectively. Only two small venae comitantes followed a course typical of the human testicular veins and these entered the posterior vena cava on the right and the renal vein on the left.

\section{AGKNOWLEDGMENTS}

The authors are grateful to Professor J. D. Lever for use of facilities in the Department of Anatomy, Mr I. M. Breckenridge for constructive criticism of the script, Mrs B. Sorrell and Mr P. F. Hire for their help in producing the diagrams, Mr L. Jones for advice with histological material and Miss P. C. Lee for secretarial assistance.

\section{REFERENCES}

BATson, O. V. (1940) The function of the vertebral veins and their role in the spread of metastases. Ann. Surg. 112, 138-149.

Franks, L. M. (1953) The spread of prostatic carcinoma to the bones. F. Path. Bact. 66, 91-93.

Fourman, J. \& Mofrat, D. B. (1971) The Blood Vessels of the Kidney. Blackwell Scientific Publications, Oxford.

Greene, E. C. (Ed.) (1968) Anatomy of the Rat. Hafner Publishing Co., New York.

Harrison, R. G. (1949a) The distribution of the vasal and cremasteric arteries to the testis and their functional importance. F. Anat. 83, 267-282.

Harrison, R. G. (1949b) The comparative anatomy of the blood supply of the mammalian testis. Proc. zool. Soc. Lond. 119, 325-344.

Kormano, M. (1967) An angiographic study of the testicular vasculature in the postnatal rat. Z. Anat. EntwGesch. 126, 138-153.

Kormano, M. (1968) Microvascular structure of the rat epididymis. Annls Med. exp. Biol. Fenn. 46, $113-118$.

MACMILLAN, E.W. (1953) Some observations on the blood supply of the epididymis in the rat and in man. Dissertation, University of Edinburgh, for M.D. thesis.

Pierrepoint, G. G. (1974) Does hormone transfer along the vasa deferentia contribute to the control of prostatic function and could it be a factor in the aetiology of prostatic hyperplasia? In Normal and Abnormal Growth of the Prostate. Ed. M. Golan. Gharles G. Thomas, Illinois. (In press).

Pierrepoint, G. G. \& Davies, P. (1973) The effect of vasectomy on the activity of prostatic RNA polymerase in rats. F. Reprod. Fert. 35, 149-152.

Pierrepoint, G. G., Davies, P., Millington, D. \& John, B. (1975) Evidence that the deferential vein transports androgens from the cauda epididymidis to the prostate and seminal vesicles of the rat. 7. Reprod. Fert. (in press).

Pierrepoint, G. G., Davies, P. \& Wilson, D. W. (1974) The rôle of the epididymis and ductus deferens in the direct and unilateral control of the prostate and seminal vesicles of the rat. F. Reprod. Fert. 41, 413-423.

Setchell, B. P. (1970) Testicular blood supply, lymphatic drainage and secretion of fluid. In The Testis, vol. I, chap. 3, pp. 101-239. Eds. A. D. Johnson, W. R. Gomes and N. L. VanDemark. Academic Press, New York.

Skinner, J. D. \& Rowson, L. E. A. (1968) Effects of testosterone injected unilaterally down the vas deferens on the accessory glands of the ram. F. Endocr. 42, 355-356. 